\title{
Characterization of the morphology of iPP/sPP blends with various compositions
}

\author{
S. Bourbigot ${ }^{1 *}$, L. Garnier ${ }^{1}$, B. Revel ${ }^{2}$, S. Duquesne ${ }^{1}$ \\ ${ }^{1}$ ISP/UMET - UMR/CNRS 8207, Ecole Nationale Supérieure de Chimie de Lille (ENSCL), Avenue Dimitri Mendeleïev \\ - Bât. C7a, BP 90108, 59652 Villeneuve d'Ascq Cedex, France \\ ${ }^{2}$ Centre Commun de Mesures RMN, Université des Sciences et Technologies de Lille, 59650 Villeneuve d'Ascq, France
}

Received 26 August 2012; accepted in revised form 8 November 2012

\begin{abstract}
The paper investigates the morphology and the structural properties of blends of isotactic polypropylene (iPP) and syndiotactic polypropylene (sPP) having different compositions using different techniques. Solid-state nuclear magnetic resonance (NMR) permits via appropriate sequence to measure the composition, conformation and dynamics, and intimacy of mixing of polymeric materials. Measurement of relaxation times gives information on local structure of phases with different mobility. The morphology is directly related to the structural organization of the blends. The crystallization rate decreases as a function of the $\mathrm{SPP}$ content. The minor component is dispersed as a nodule in the main component of the blend and it plays the role of nucleating agent on it. Besides, morphology changes occur for the composition 50/50 (wt/wt) of the blend iPP/sPP. Different phases are identified, namely free amorphous, constrained amorphous and crystalline regions which exhibit different molecular mobilities. It is also shown at the interphase matrix-nodules, the nodules create a constrained amorphous zone.
\end{abstract}

Keywords: polymer blends, syndiotactic polypropylene, isotactic polypropylene, morphology

\section{Introduction}

Syndiotactic polypropylene (sPP) was first synthesized in the early 1960s with a Ziegler Natta catalyst [1]. Unfortunately, this new stereoregular polypropylene exhibited low syndiotacticity and had poor mechanical and thermal properties which prevented it for many applications. The use of new metallocene catalysts allowed Ewen et al. [2] to synthesize a sPP with high tacticity in 1988. This new sPP exhibits superior properties including toughness and excellent elastic behavior [3]. The excellent elastic properties of sPP are based upon a phase transition occurring in the crystalline regions during stretching (four crystalline forms have been found for sPP). In the most stable forms (form I and form II), chains are in a helical conformation while they are in a trans-planar conformation in the metastable forms III and IV. Previous investigations found that stretching of sPP blends and fibers induce a transition from the stable form I or II to form III. This transition is reversible because form I or II is again obtained when the applied stress is removed [4]. However, besides its excellent elastic properties sPP exhibits many disadvantages such as poor mechanical properties, very complicated polymorphism and slow crystallization rate $[5,6]$.

Blending sPP with another material having better mechanical properties and a faster crystallization rate can be an alternative for improving processing of sPP. So, investigations have been performed on sPP blends with isotactic polypropylene (iPP). Thomman et al. [7] found that $\mathrm{iPP} / \mathrm{sPP}$ blends are

\footnotetext{
${ }^{*}$ Corresponding author, e-mail: serge.bourbigot@ensc-lille.fr (C) BME-PT
} 
phase separated. They showed that crystallization of iPP and sPP occurs separately and that crystallization of $\mathrm{iPP} / \mathrm{sPP}$ blend is dependent on the crystallization nature of the neat components. An iPP matrix with a dispersed SPP phase or a SPP matrix with an iPP dispersed phase can be obtained as a function of the blend composition. A co-continuous morphology was also found for nearly equi-mass compositions. Those results were then confirmed by Clancy et al. [8] by numerical simulation. Using the method of equilibrium melting points, Woo et al. [9] assessed the Flory-Huggins interaction parameter of the sPP/iPP blend and they found it was nearly zero indicating that the interactions in the blend are weak. They suggest a state of mixture bordering on phase separation or in other words, the blend $\mathrm{iPP} / \mathrm{sPP}$ is immiscible. It is also confirmed by Phillips [10] and by Wang et al. [11] on iPP/sPP blend of composition 50/50 (wt/wt). Zou et al. [12] also examined this composition and its behavior during injection-molding. They found a dispersed structure in the skin layer and a co-continuous structure in the core layer. It was explained by the difference of crystallization temperature of iPP and sPP inducing a migration phenomenon and creating then composition inhomogeneity in the blend. Zhang et al. [5] report similar conclusions for different compositions of iPP/sPP investigating morphology and mechanical behavior of iPP/sPP blends and fibers. However, they suggest that the amorphous phases of iPP and sPP might be partially interconnected. This interconnection is also suggested by Gorrasi et al. [13] examining mechanical properties of $\mathrm{iPP} / \mathrm{sPP}$ fibers. Finally, the miscibility of the iPP/sPP blends was investigated by NMR and rheology by Zheng et al. [14]. They confirmed the immiscibility of the blends for a wide range of composition but they found for compositions containing a low amount of sPP (iPP/sPP 90/10 (wt/wt)) that no phase separation was observed. They explained this miscibility by the existence of intermolecular chain interactions between sPP and iPP components in the solid state. Although many investigations have been done on morphology of $\mathrm{iPP} / \mathrm{sPP}$ blends, questions remain and it is the goal of this paper to investigate the structure and the morphology of iPP/sPP blends of various compositions. Solid-state nuclear magnetic resonance (NMR) is a powerful method for measuring the composition, conformation and dynamics, and intimacy of mixing of solid materials. In particular in the case of polymeric blends, NMR permits to analyze the miscibility, phase structure, and heterogeneity of polymer mixtures on a molecular scale $[15,16]$. It is especially useful in polymeric blend systems containing complex phase structures that may exist beyond the resolution limits of traditional microscopic or thermal analyses. Many different NMR parameters can be used to study molecular motions like relaxation times. The relaxation times of ${ }^{1} \mathrm{H}$ nucleus contain a large amount of information on the dynamics. It can be expected measuring relaxation times to get information on local structure of phases with different mobilities. In particular, spin-lattice relaxation times are very sensitive to the short spatial proximity of interacting dipole moments of the protons. Wide-line ${ }^{1} \mathrm{H}$ NMR permits the determination of different phases, interphases and the measurement of the crystallinity in polymers [1719]. High-resolution solid-state ${ }^{13} \mathrm{C} N \mathrm{NR}$ is a selective method that permits following the motional behavior of each carbon of the repeat unit independently $[20,21]$. From those measurements, two useful proton spin-relaxation times can be obtained: the spin lattice relaxation times in the laboratory frame, $T_{1}$, and in the rotating frame, $T_{1 p}$. The length scale of heterogeneity - from a few nanometers to tens of nanometers - can be evaluated approximately from their values to allow measurements of compositional heterogeneity on length scales limited by spin diffusion [22].

This paper is organized in three parts. The first part will examine the morphology of blends iPP/sPP of different composition by electronic microscopy. Structural analyses of the blends will be then done using different techniques like scanning differential calorimetry (DSC), high resolution solid state NMR and wide-angle X-ray diffraction (WAXD). The third part is devoted to the investigations of the molecular dynamic in the blends iPP/sPP by solid state NMR.

\section{Experimental}

\subsection{Materials}

Commercial grades of isotactic polypropylene and syndiotactic polypropylene were used in this study. iPP (PPH9069) and sPP (Finaplas 1751) were supplied by Total petrochemicals (Feluy, Belgium). PPH9069 has a melt flow rate (MFR) for a load of $2.16 \mathrm{~g}$ at $230^{\circ} \mathrm{C}$ of $25 \mathrm{~g} / 10 \mathrm{~min}$ whereas MFR of Finaplas 1751 is $20 \mathrm{~g} / 10 \mathrm{~min}$. Blends of $\mathrm{iPP} / \mathrm{sPP}$ 
$(75 / 25,50 / 50,40 / 60,30 / 70,25 / 75 \mathrm{wt} / \mathrm{wt})$ were prepared in a Brabender mixer at $190^{\circ} \mathrm{C}$ for 12 minutes with a shear rate of $50 \mathrm{rpm}$. Homopolymers of iPP and sPP were identically prepared in order to have blends and homopolymers with the same thermal history. Virgin polypropylenes and blends were ground to powder using a cryogenic crushing unit. All analyses (except electron microscopy) were performed with the prepared powder.

\subsection{Electron microscopy}

Scanning electron microscopy (SEM) was performed using a Hitachi S4700 microscope (Verrières-le-Buisson, France). All samples (piece of material got after melt-mixing) were cryo-fractured in liquid nitrogen before analysis. The fractured surface was observed with secondary electrons at $6 \mathrm{kV}, 10 \mu \mathrm{A}$ to get SEM images of the blends.

For transmission electron microscopy (TEM), all samples (piece of material got after melt-mixing) were ultra microtomed with a diamond knife on a Leica ultracut UCT microtome, at room temperature to give sections with a nominal thickness of $70 \mathrm{~nm}$. Surface of the samples was then stained with $\mathrm{RuO}_{4}$. Sections were transferred to $\mathrm{Cu}$ grids of 400 meshes. Bright-field TEM images of nanocomposites were obtained at $200 \mathrm{kV}$ under low dose conditions with a Philips CM30 electron microscope (Zaventem, Belgium), using a Gatan CCD camera. Low magnification images were taken at $17000 \times$ and high-magnification images were taken at $100000 \times$.

\subsection{Differential scanning calorimetry (DSC)}

Non isothermal crystallization kinetics of iPP/sPP blends were investigated by DSC using a TA Instruments Q100 Calorimeter (Guyancourt, France). All measurements were performed in nitrogen (nitrogen flow $=50 \mathrm{~mL} / \mathrm{min}$ ) to avoid degradation of the $\mathrm{iPP} / \mathrm{sPP}$ blend upon heating. $8.3 \pm 0.1 \mathrm{mg}$ of each sample were put in a sealed aluminum pan. Samples were first heated up from 25 to $200^{\circ} \mathrm{C}$ at a rate of $10^{\circ} \mathrm{C} / \mathrm{min}$ and held for 10 minutes to erase thermal history of the blend. Samples were then cooled down at $10^{\circ} \mathrm{C} / \mathrm{min}$. Calculation of the degree of crystallinity of iPP $\left(\chi_{\mathrm{c}, \mathrm{iPP}}\right)$ and $\mathrm{sPP}\left(\chi_{\mathrm{c}, \mathrm{sPP}}\right)$ has been done as Equations (1) and (2):

$$
\chi_{\mathrm{c}, \mathrm{PP}}=\frac{\Delta H_{\mathrm{f}, \mathrm{iPP}}}{\Delta H_{\mathrm{f}, \mathrm{iPP}}^{0} \cdot w t \%_{\mathrm{iPP}}}
$$

$\chi_{\mathrm{c}, \mathrm{sPP}}=\frac{\Delta H_{\mathrm{f}, \mathrm{sPP}}}{\Delta H_{\mathrm{f}, \mathrm{sPP}}^{0} \cdot w t \%_{\mathrm{sPP}}}$

where $\Delta H_{\mathrm{f}, \text { iPP }}$ is the melting enthalpy of iPP (area of the melting endotherm of iPP), $\Delta H_{\mathrm{f}, \mathrm{sPP}}$ is the melting enthalpy of sPP (area of the melting endotherm of sPP). $\Delta H_{\mathrm{f}, \mathrm{iPP}}^{0}$ et $\Delta H_{\mathrm{f}, \mathrm{sPP}}^{0}$ are the melting enthalpies of iPP and sPP exhibiting $100 \%$ crystallinity and equaling 209 and $196 \mathrm{~J} / \mathrm{g}$ respectively [5, 23-25]. 'wt\% iPP' and 'wt\% sPP' are the mass composition of the mixture. The degree of crystallinity of the blends has been calculated as follows (Equation (3)):

$\chi_{\mathrm{c}, \text { mixture }}=\chi_{\mathrm{c}, \mathrm{iPP}} \cdot w t \%_{\mathrm{iPP}}+\chi_{\mathrm{c}, \mathrm{sPP}} \cdot w t \%_{\mathrm{sPP}}$

\subsection{Wide-angle $X$-ray diffraction (WAXD)}

WAXD spectra were recorded in the $10-80^{\circ} 2 \theta$ range using a Bruker AXS D8 diffractometer (Champs-sur-Marne, France) $\left(\lambda_{(\mathrm{Cu} \mathrm{K} \alpha)}=1.5418 \AA\right.$, $40 \mathrm{keV}, 25 \mathrm{~mA}$ ) in configuration $2 \theta / \theta$. The acquisition parameters were as follows: a step of $0.02^{\circ}$, a step time of $2 \mathrm{~s}$. The data are analyzed using the diffraction patterns of inorganic crystal structure database (ICSD).

\subsection{Solid state nuclear magnetic resonance (NMR)}

High-resolution solid-state ${ }^{13} \mathrm{C}$ NMR spectra were recorded at $100.63 \mathrm{MHz}$ using a Bruker Avance 400 spectrometer (9.4 T) (Wissembourg, France). A variable temperature $4 \mathrm{~mm}$ magic angle spinning (MAS) probe head was used. Samples were packed in zirconium dioxide rotors closed with boron nitride caps and spun at $10 \mathrm{kHz}$ unless otherwise specified. The inner spinner volume was approximately $0.1 \mathrm{~cm}^{3}$. All spectra were obtained by cross-polarization (CP) from the spin-locked protons, followed by high-power proton dipolar decoupling (DD). The matched spin-locked cross-polarization transfers were carried out with ${ }^{1} \mathrm{H}$ magnetic field strength of $55 \mathrm{kHz}$, corresponding to $\pi / 2$ pulse duration of $3.5 \mu \mathrm{s}$. The Hartmann-Hahn condition was matched using glycine. Chemical shift calibrations were performed using the glycine ( $\alpha$-form) carbonyl carbon resonance at $176.03 \mathrm{ppm}$. Contact time and repetition time were $1 \mathrm{~ms}$ and $5 \mathrm{~s}$, respectively. About 1024 scans were needed to obtain a suitable signalto-noise ratio. Rotating frame spin-lattice relax- 
ation times $T_{1 \rho}(\mathrm{C})$ were also measured at different temperatures $\left(25,50,80\right.$ and $\left.100^{\circ} \mathrm{C}\right)$. A spin locking experiment was performed under $\mathrm{CP}$ and MAS conditions and the spin-lock pulse was up to $50 \mathrm{~ms} .{ }^{13} \mathrm{C}$ spins were locked with the field of $64 \mathrm{kHz}$.

Low-resolution ${ }^{1} \mathrm{H}$ NMR experiments were carried out on the same spectrometer as above using a $4 \mathrm{~mm}$ static Bruker probe, with a ${ }^{1} \mathrm{H} \pi / 2$ pulse length of $2.5 \mu$ s corresponding to magnetic field strength of $100 \mathrm{kHz}$. Spin-lattice relaxation times in the laboratory frame, $T_{1}\left({ }^{1} \mathrm{H}\right)$, were measured using the saturation-recovery pulse sequence with direct proton observation. Three closely spaced $90^{\circ}$ pulses accomplished the saturation. Spin-lattice relaxation times, $T_{1 \rho}\left({ }^{1} \mathrm{H}\right)$, in the rotating frame were determined with a $\pi / 2$ spin-lock experiment with a spin-locking field corresponding to $50 \mathrm{kHz}$ for $4.8 \mu \mathrm{s}$. Measurements of all relaxation times were also performed at various temperatures $\left(25,50,80\right.$ and $\left.100^{\circ} \mathrm{C}\right)$.

\section{Results and discussion}

\subsection{Morphology of the blends iPP/sPP}

SEM images of virgin iPP and sPP are similar and no significant difference of morphology is revealed between the two samples (not shown). The morphologies of the blends $75 / 25$ and $50 / 50$ show the presence of two phases (Figure 1). The blend 75/25 exhibits a continuous phase (polymeric matrix) in which an additional phase is dispersed with a circular shape of different sizes (nodules are shown by circles on Figure 1a). In this blend, iPP is the main component and the continuous phase is assigned to it and the nodules are assigned to sPP. It is worth to note a different surface aspect between the two phases: the nodules exhibit rough surface while the continuous phase looks smooth. The blend 50/50

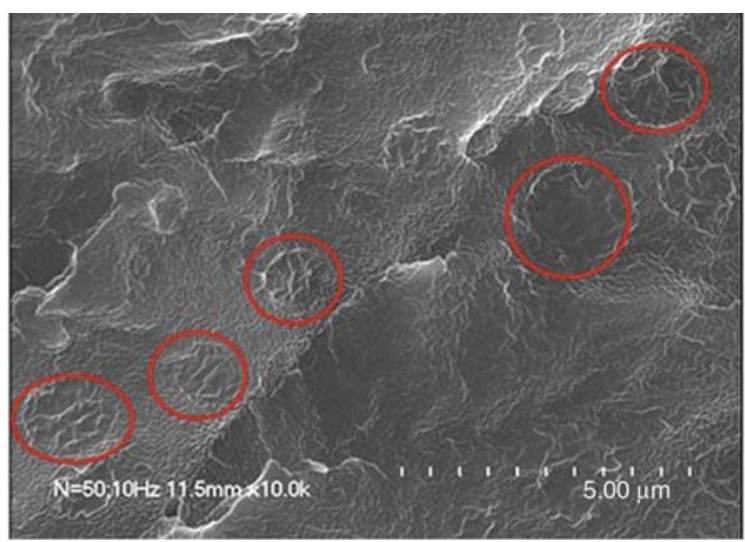

a) shows a different morphology compared to the blend $75 / 25$ (Figure 1b). The nodules are larger in size (4$5 \mu \mathrm{m}$ in average compared to $1-2 \mu \mathrm{m}$ for the blend $75 / 25$ ) and they are more ovoid than spherical. It indicates the general morphology turns into two cocontinuous phases which is characteristic of immiscible blends having equal mass compositions.

The morphologies of the blends $40 / 60$ and 30/70 are almost similar to those of the blend $75 / 25$. The presence of continuous phase containing a dispersed phase with nodules having spherical shapes of different sizes is observed (Figure 2). Taking into account the blends' compositions, the continuous phase is assigned to sPP while the dispersed phase (nodules) is assigned to iPP. This assignment is confirmed noticing the nodules exhibit a smooth aspect while the continuous phase exhibits a rough surface. The opposite (in terms of aspect) was observed in the case of the blend $75 / 25$. The nodules of the blend $40 / 70$ are of 1 to $4 \mu \mathrm{m}$ in size which are similar to those measured for the blend 50/50 (Figure 2a). The nodules of the blend 30/70 are smaller in size (1$2 \mu \mathrm{m}$ in size) which is similar to those of the blend $75 / 25$. These results indicate therefore the size of the nodules increases as a function of the concentration of the dispersed phase.

In order to confirm the assignments done from the SEM images, the morphologies have been then examined by TEM on samples stained by $\mathrm{RuO}_{4}$. It permits to highlight the amorphous zones since it appears as dark zones on TEM images. Remarking that sPP exhibits low crystallinity, it should appear mainly in the dark zones permitting to distinguish between iPP and sPP (Figure 3-5).

As already observed by SEM, TEM images reveal that the blends iPP/sPP exhibit morphology consti-

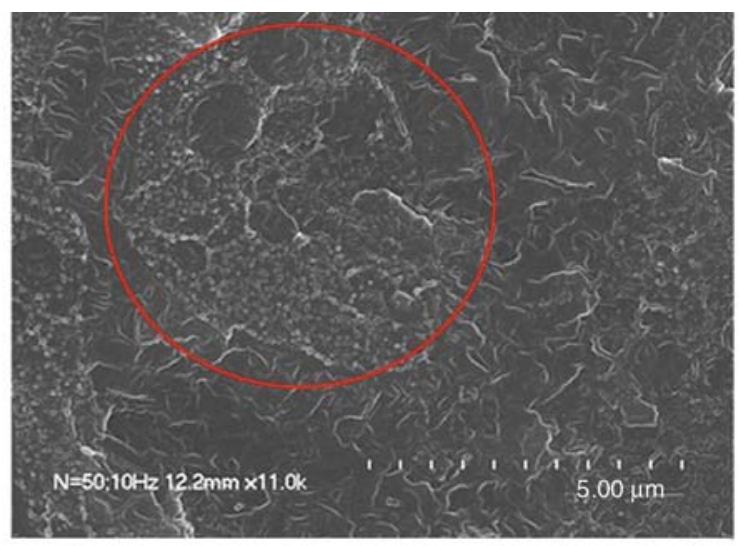

b)

Figure 1. SEM images of cryo-fracturated surfaces of the blends iPP/sPP at (a) 75/25 and (b) 50/50 (nodules are in circles) 


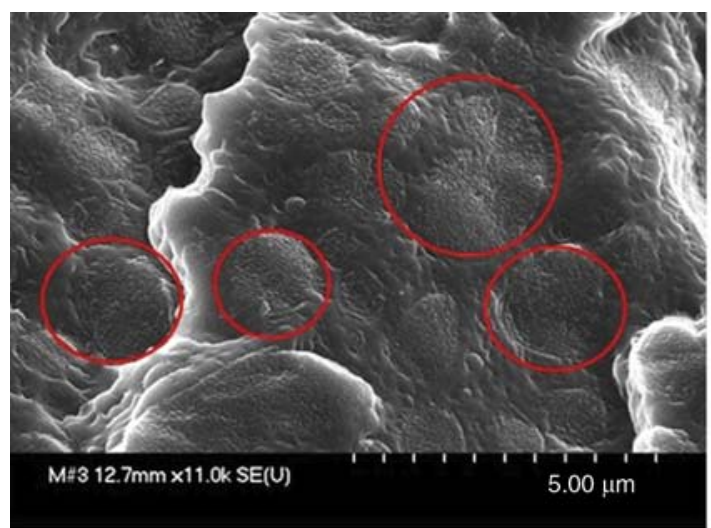

a)

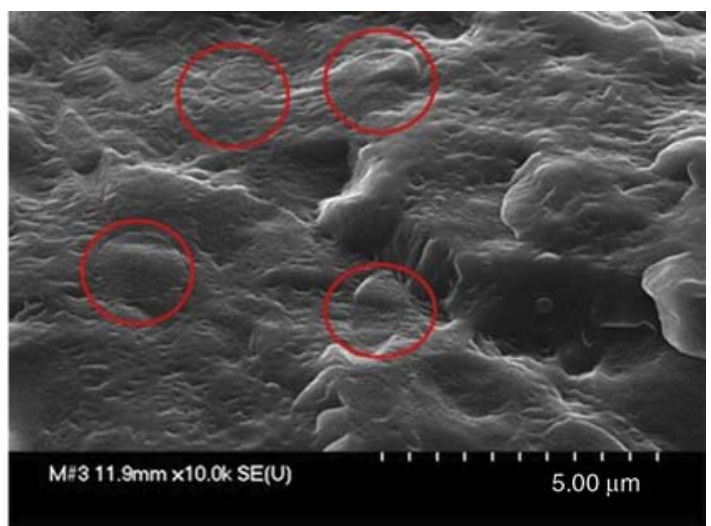

b)

Figure 2. SEM images of cryo-fracturated surfaces of the blends iPP/sPP at (a) 40/60 and (b) 30/70 (nodules are in circles)

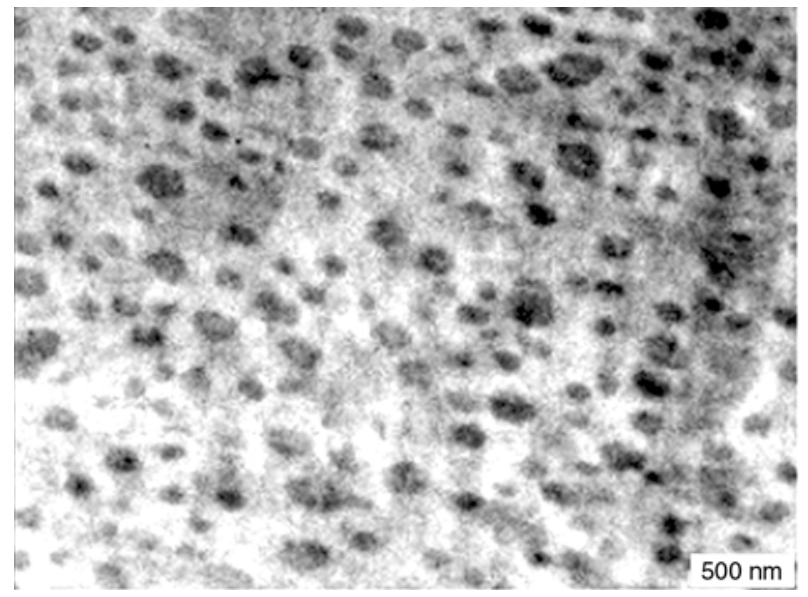

Figure 3. TEM image of the blend iPP/sPP 75/25 $(\times 5000)$

tuted by a continuous phase in which there is a dispersed phase (dispersed nodules). In the case of the blend 75/25, the nodules are elliptic in shape (Figure 3). The black color confirms that the dispersed phase is constituted by sPP. It is noteworthy that some zones in the continuous phase are darker suggesting iPP is not highly crystalline (this aspect will be discussed in the following). On the contrary, the

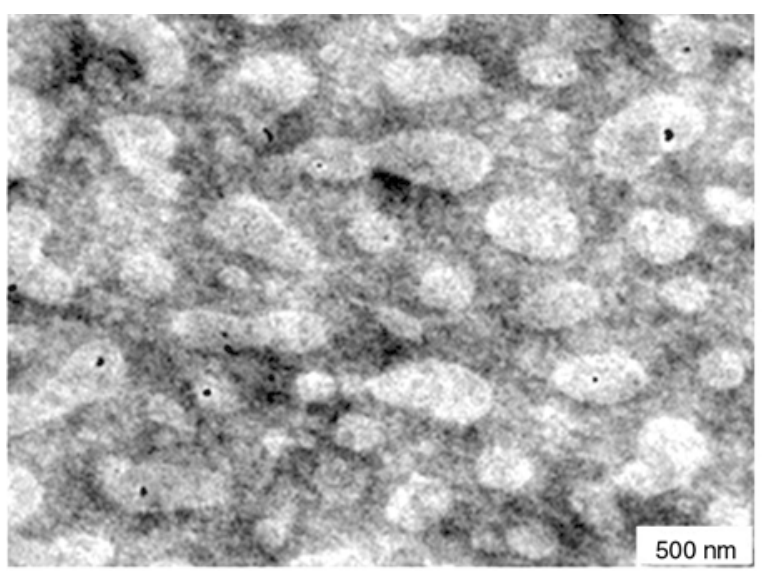

a) dark zones of the blends $40 / 60$ and $30 / 70$ correspond to the continuous phase while the nodules are the bright zones (Figure 4). Hence it is confirmed that the blends $40 / 60$ and $30 / 70$ are constituted by a continuous phase of sPP in which nodules of iPP are dispersed. The nodules in the blend 40/60 exhibit various shapes and sizes. Finally in the blend 50/50, the continuous phase is constituted by iPP and the dispersed phase is SPP (Figure 5). The nodules exhibit various shapes and their sizes are larger compared to those of the other blends. Coalescence phenomenon is clearly shown on Figure 5 evidencing that the blend turns into two co-continuous phases as suggested by SEM. According to this TEM study, the co-continuous structure should be obtained for composition lying between 50/50 and 40/60.

\subsection{Structural analysis of the blends iPP/sPP}

SEM and TEM analyses have shown that the morphology of the blends iPP/sPP is bi-phasic. It can be then expected that structural changes can be induced by the different morphologies of the blends and it is

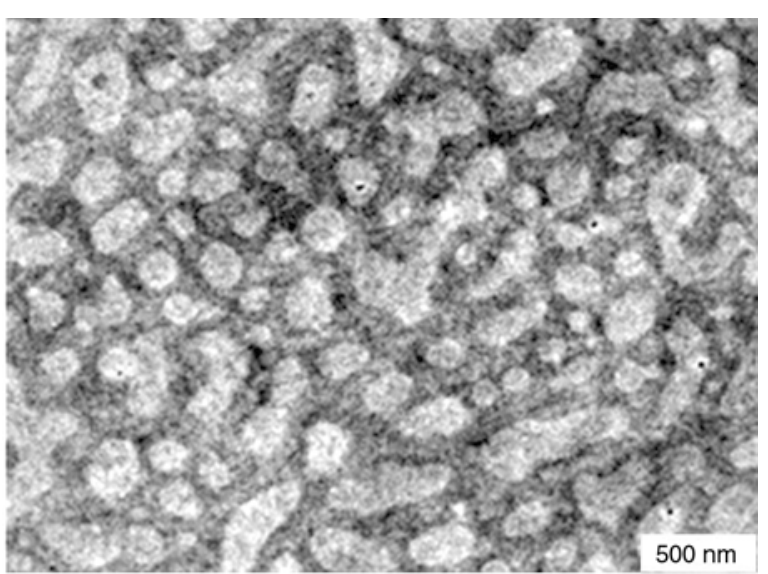

b)

Figure 4. TEM images of the blends iPP/sPP at (a) 30/70 and (b) 40/60 (×5000) 


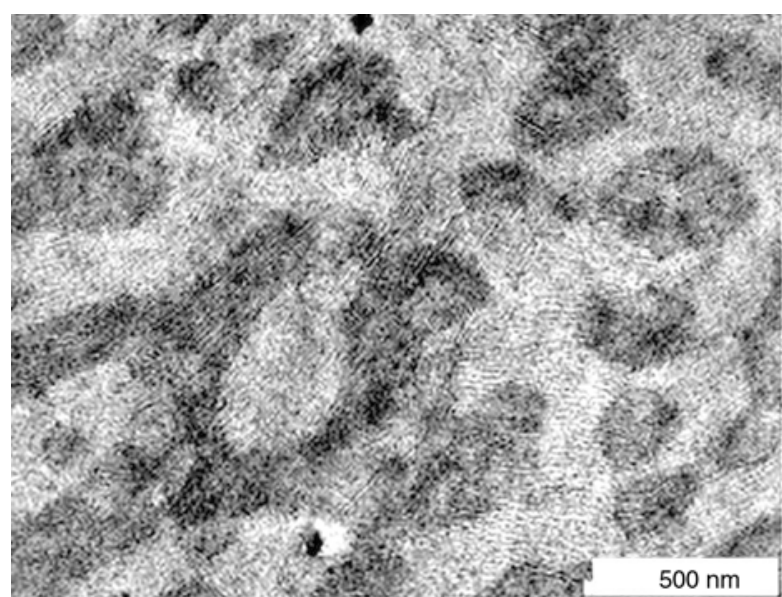

a)

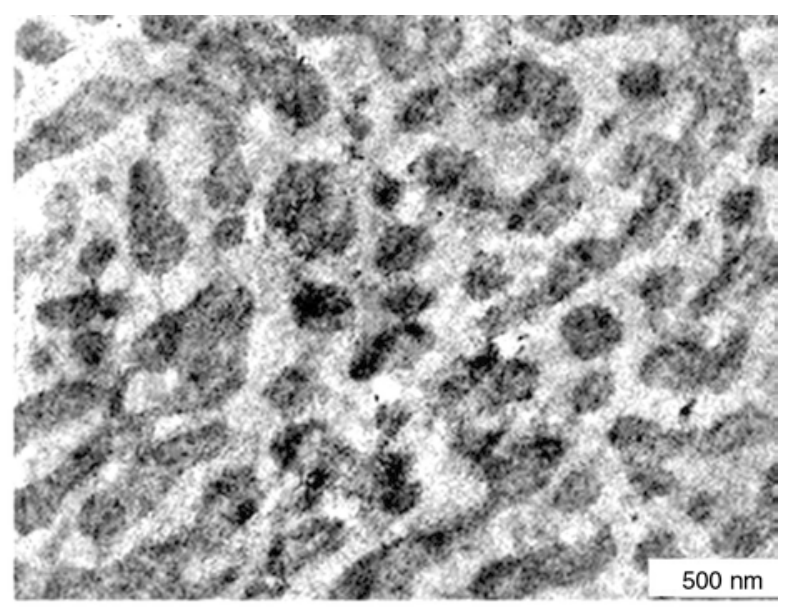

b)

Figure 5. TEM images of the blends iPP/sPP at 50/50 at (a) $\times 10000$ and (b) $\times 5000$

the purpose of this section to investigate this using DSC, WAXD and high resolution solid state 13C NMR.

\subsubsection{DSC analysis}

The temperatures of crystallization of the blends $\mathrm{iPP} / \mathrm{sPP}$ have been determined by DSC during the cooling of the samples (Table 1). The DSC thermograms (not shown) exhibit two distinct exotherms corresponding to the crystallization of the two components of the blend. It shows therefore that iPP and sPP does not co-crystallize but on the contrary they crystallize separately. iPP crystallizes in the temperature range of $110-120^{\circ} \mathrm{C}$ while sPP crystallizes in the temperature range of $85-95^{\circ} \mathrm{C}$. A shift in the crystallization temperatures of iPP and $\mathrm{sPP}$ in the blends is observed compared to the virgin polypropylenes. The incorporation of iPP in the blend up to the composition 50/50 increases $T_{\mathrm{c}, \mathrm{sPP}}$ and it favors the crystallization of sPP. In our previous work [26] on the crystallization kinetics of iPP/sPP blends, it was suggested that the incorporation of sPP in iPP promotes the formation of crystallization defaults which can act as nucleating sites. The crys-

Table 1. Crystallization temperatures measured by DSC of the blends iPP/sPP where $T_{\mathrm{c}, \text { iPP }}$ and $T_{\mathrm{c}, \mathrm{sPP}}$ are the temperatures of crystallization of iPP and sPP respectively

\begin{tabular}{|l|c|c|}
\hline \multicolumn{1}{|c|}{ Blend } & $\begin{array}{c}\mathbf{T}_{\mathbf{c}, \mathbf{i P P}} \\
{\left[{ }^{\circ} \mathbf{C}\right]}\end{array}$ & $\begin{array}{c}\mathbf{T}_{\mathbf{c}, \mathbf{s P P}} \\
{\left[{ }^{\circ} \mathbf{C}\right]}\end{array}$ \\
\hline $100 / 0$ (virgin iPP) & 117.2 & - \\
\hline $75 / 25$ & 121.9 & 90.1 \\
\hline $50 / 50$ & 120.5 & 95.7 \\
\hline $40 / 60$ & 114.4 & 88.4 \\
\hline $30 / 70$ & 112.1 & 88.8 \\
\hline $0 / 100$ (virgin sPP) & - & 85.9 \\
\hline
\end{tabular}

tallization is enhanced while sPP is in the dispersed phase and hence sPP exhibits higher crystallization temperatures until the composition reaches 50/50. It is also true in the case of incorporating $\mathrm{SPP}$ in iPP since a shift of $T_{\mathrm{c}, \text { iPP }}$ is observed towards higher temperatures. Nevertheless from the blend 40/60, $T_{\mathrm{c}, \text { iPP }}$ is lower than that of virgin iPP. These results evidence the immiscibility of the crystalline phases of iPP and sPP in the blends iPP/sPP but the shifts of the crystallization temperatures indicates intermolecular interactions between the two components.

Figure 6 shows DSC thermograms of the blends iPP/sPP during heating (melting cycle). Two distinct melting zones can be distinguished corresponding to the melting of the two components of the blend: (i) an endotherm at about $160^{\circ} \mathrm{C}$ assigned to the melting of iPP and (ii) a double endotherm at about $120-130^{\circ} \mathrm{C}$ assigned to the melting of sPP. The presence of these distinct two melting zones

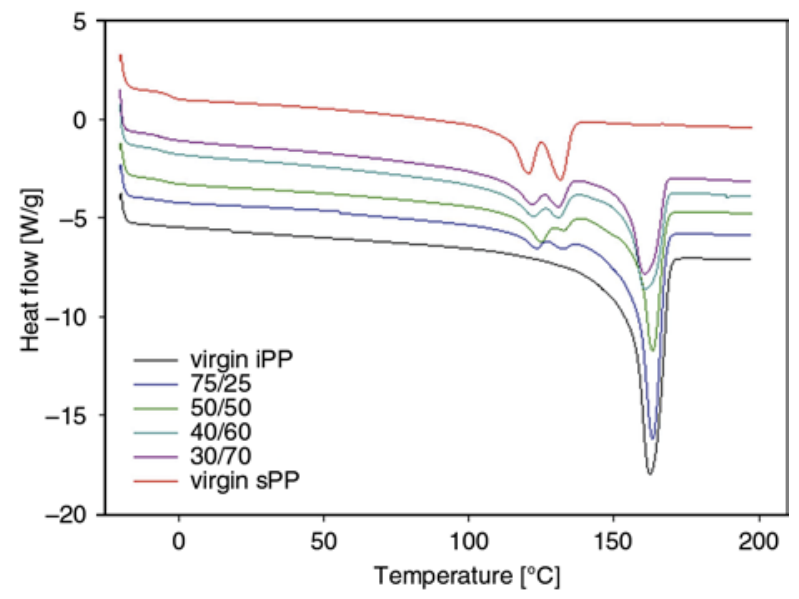

Figure 6. DSC thermograms of the blends iPP/sPP compared to virgin iPP and sPP during heating 
confirms the conclusions made from the crystallization of the blends. The double endotherm is assigned to the characteristic behavior of the melting of the polymeric sPP chains in helical conformation (form I and/or II). It is indeed very rare under classical crystallization conditions to get stable crystalline forms (forms I or II) without defects. So, the first endotherm (at about $120^{\circ} \mathrm{C}$ ) corresponds to the melting of defects and the second one (at about $130^{\circ} \mathrm{C}$ ) is assigned to the melting of the polymeric chains without defects [5].

The degrees of crystallinity, $\chi_{\mathrm{c}}$, have been calculated from the melting endotherms and they are listed in Table 2. It is observed that whatever the composition of the blend, the degree of crystallinity of iPP is always higher than that of sPP. It was expected because sPP exhibits usually low degree of crystallinity especially compared to iPP. Besides, the degree of crystallinity of iPP decreases when the concentration of sPP increases up to 50/50 in the blend. The trend is inversed at low concentration of iPP in the blend iPP/sPP (blends at 40/60 and $30 / 70$ ), the degree of crystallinity of iPP increases and it is even higher for the blend 30/70 than that of virgin iPP. In the case of sPP, its degree of crystallinity decreases with the incorporation of iPP in the blend but the influence of the composition is less than in the case of iPP.

Glass transition temperatures, $T_{\mathrm{g}}$, of the blends iPP/ sPP determined on the DSC thermograms (graphs not shown) are listed in Table 3. It is noteworthy that only one $T_{\mathrm{g}}$ is observed for all samples. It is recognized that immiscible blends like iPP/sPP should exhibit two distinct Tg. The miscibility of the two amorphous phases of $\mathrm{iPP} / \mathrm{sPP}$ could explain it but no evidence is given for this (it is discussed in the following). The signal corresponding to the $T_{\mathrm{g}}$ of iPP is of very low intensity and it is reasonable to assume it is not detectable in the blend.
Table 3. Glass transition temperature measured by DSC of the blends iPP/sPP compared to virgin polypropylenes

\begin{tabular}{|l|c|}
\hline \multicolumn{1}{|c|}{ Blend } & $\begin{array}{c}\text { Glass transition temperature }\left(\mathbf{T}_{\mathrm{g}}\right) \\
{\left[{ }^{\circ} \mathbf{C}\right]}\end{array}$ \\
\hline Virgin iPP & -10.1 \\
\hline $75 / 25$ & -4.2 \\
\hline $50 / 50$ & -4.2 \\
\hline $40 / 60$ & -2.8 \\
\hline $30 / 70$ & -2.8 \\
\hline Virgin sPP & -3.1 \\
\hline
\end{tabular}

\subsubsection{High resolution solid state ${ }^{13} \mathrm{C}$ NMR}

In order to characterize further the crystalline forms of the blends, CP-DD MAS ${ }^{13} \mathrm{C}$ NMR have been performed (Figure 7).

The NMR spectrum of virgin iPP exhibit three bands located at 44.5, 26.5 and $22.5 \mathrm{ppm}$ which are assigned to $\mathrm{CH}_{2}, \mathrm{CH}$ and $\mathrm{CH}_{3}$ groups. The bands assigned to methylene and methyl group show splits which are characteristic of $\alpha$ crystalline form of iPP. Those splits have a theoretical ratio of 2 to 1

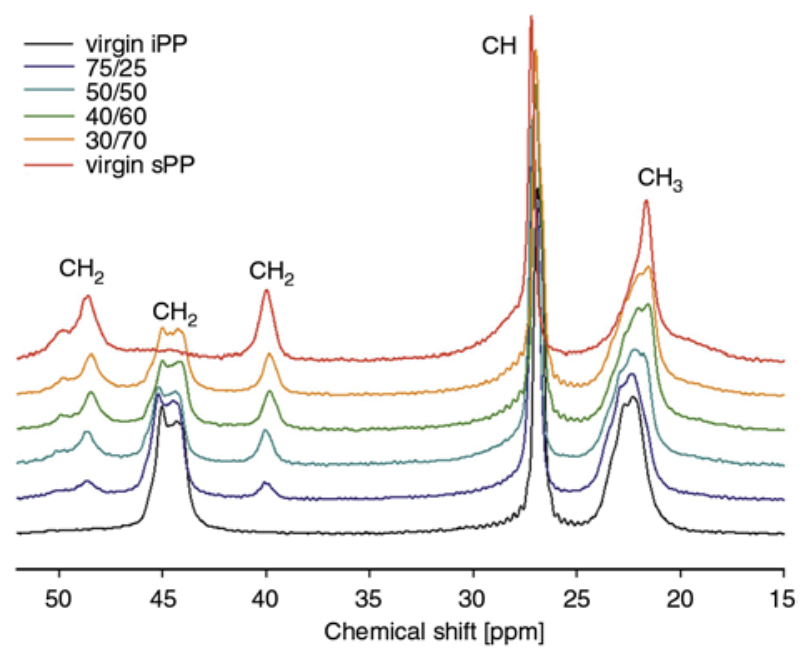

Figure 7. CP-DD MAS ${ }^{13} \mathrm{C}$ NMR spectra of the blends $\mathrm{iPP} / \mathrm{sPP}$ compared to virgin iPP and sPP

Table 2. Crystallization rates and crystallization enthalpies measured by DSC of the blends iPP/sPP compared to virgin polypropylenes where $\Delta H_{\mathrm{c}}$ is the crystallization enthalpy (with the subscript iPP and sPP corresponding to iPP and sPP respectively) and $\chi_{\mathrm{c}}$ is the crystallization rate (with the subscript iPP and sPP corresponding to iPP and sPP respectively)

\begin{tabular}{|l|c|c|c|c|c|}
\hline \multicolumn{1}{|c|}{ Blend } & $\begin{array}{c}\Delta \mathbf{H}_{\mathbf{c}, \text { iPP }} \\
{[\mathbf{J} / \mathbf{g}]}\end{array}$ & $\begin{array}{c}\chi_{\mathbf{c}, \mathbf{i P P}}[\mathbf{\%}] \\
\text { Virgin iPP }\end{array}$ & $\begin{array}{c}\Delta \mathbf{H}_{\mathbf{c}, \mathbf{s P P}} \\
{[\mathbf{J} / \mathbf{g}]}\end{array}$ & $\begin{array}{c}\chi_{\mathbf{c}, \mathbf{s P P}} \\
{[\mathbf{\%}]}\end{array}$ & $\begin{array}{c}\chi_{\mathbf{c}, \text { total }} \\
{[\mathbf{\%}]}\end{array}$ \\
\hline $75 / 25$ & 100.8 & $48.2 \pm 0.7$ & - & - & $48.2 \pm 0.7$ \\
\hline $50 / 50$ & 62.9 & $40.1 \pm 1.6$ & 4.5 & $9.2 \pm 0.8$ & $32.4 \pm 0.1$ \\
\hline $40 / 60$ & 43.0 & $41.1 \pm 0.2$ & 13.0 & $13.3 \pm 0.5$ & $27.2 \pm 0.2$ \\
\hline $30 / 70$ & 37.8 & $45.2 \pm 0.7$ & 14.5 & $12.3 \pm 0.6$ & $25.5 \pm 0.5$ \\
\hline Virgin sPP & 35.3 & $56.3 \pm 1.8$ & 15.8 & $11.5 \pm 1.6$ & $24.9 \pm 1.1$ \\
\hline
\end{tabular}


corresponding to the presence of two sites in the $\alpha$ crystalline form of iPP [27]. This crystalline form was expected since it is that obtained in usual crystallization conditions.

The NMR spectrum of virgin sPP exhibit four bands located at 48.5, 39.8, 26.1 and $22.1 \mathrm{ppm}$. The bands at 26.1 and $22.1 \mathrm{ppm}$ are assigned to resonances of $\mathrm{CH}$ and $\mathrm{CH}_{3}$ groups and those at 48.5 and 39.8 ppm correspond to $\mathrm{C}$ resonances in $\mathrm{CH}_{2}$ groups in helical $4_{1}$ conformation (crystalline form I and/or II). The explanation of having two bands is all carbons of $\mathrm{CH}_{2}$ are not conformationally equivalent. According to the literature $[4,28]$, the two signals correspond to $\mathrm{CH}_{2}$ in conformations tggt and gttg. The shift of $8.7 \mathrm{ppm}$ between those two bands are characteristic of two $\gamma$-gauche effects [28]. It evidences therefore that the crystalline chains of sPP are mainly in helical conformation. It is noteworthy that shoulders are located at 50.1 and $40.5 \mathrm{ppm}$ and the broadening of bands of methene and methyl groups and low intense and broad band around $44.5 \mathrm{ppm}$. From previous works [4], those broad bands are assigned to the contribution of polymeric chains in amorphous phases.

On the MAS ${ }^{13} \mathrm{C}$ NMR spectra of the blends iPP/sPP, characteristic bands of iPP and sPP are observed: bands assigned to $\mathrm{CH}_{2}, \mathrm{CH}$ and $\mathrm{CH}_{3}$ groups of iPP located at 44.5, 26.5 and $22.5 \mathrm{ppm}$ and also bands' splitting at 44.5 and $22.5 \mathrm{ppm}$ characteristic of the $\alpha$ form of iPP. Bands of sPP are detected at 48.5, 39.8, 26.1 and $22 \mathrm{ppm}$ assigned to polymeric chains of sPP in helical conformation. It is noteworthy that bands assigned to $\mathrm{CH}$ and $\mathrm{CH}_{3}$ belonging to iPP and to $\mathrm{SPP}$ overlaps in the blends $\mathrm{iPP} / \mathrm{sPP}$. A shoulder is also observed on the spectra at $50.1 \mathrm{ppm}$ together with the broadening of bands of $\mathrm{CH}$ and $\mathrm{CH}_{3}$ corresponding to the contributions of amorphous chains. In the blends iPP/sPP and virgin iPP, iPP crystallizes in $\alpha$ form while crystalline sPP chains are mainly in conformations of type helical $4_{1}$. The amorphous chains of sPP are in various conformations as indicated by broad bands detected by MAS ${ }^{13} \mathrm{C}$ NMR. The mixing of iPP with sPP does not influence the crystalline forms obtained. Nevertheless, it is very difficult to distinguish between the crystalline form I and II from MAS ${ }^{13} \mathrm{C} N M R$ because the chains are in helical conformations in the two cases. To get additional information, investigations by X-ray diffraction will be performed in the next section.

\subsubsection{Wide-angle $X$-ray diffraction}

X-ray patterns of iPP and sPP (not shown) exhibit in the two cases, diffraction peaks superimposed on a broad band. The broad band is assigned to the scattering of the iPP and sPP amorphous phases and the diffraction peaks are assigned to the diffraction of the crystallites of iPP and sPP. The diffraction peaks detected on the X-ray pattern of iPP are characteristic of the crystalline $\alpha$ form of iPP and those detected on the X-ray pattern of sPP are characteristic of the crystalline form I of sPP. It is noteworthy that the $\mathrm{X}$-ray pattern of sPP does not reveal the diffraction peak at $2 \theta=18.8^{\circ}(211)$. Its absence is assigned to the presence of defects in the chains' packing in the orthorhombic phase characteristic of form I [4]. This is consistent with DSC results showing a double melting endotherm assigned to the melting of defects in the crystalline form I.

X-ray patterns of the different blends (not shown) reveal the contributions of each component. The intensities of the peaks vary as function of the composition of the blend. It is shown that iPP crystallizes under the $\alpha$ form and that sPP crystallizes under the form I whatever the blend iPP/sPP considered. It indicates that the blending of iPP and sPP does not seem to have a significant influence on their respective crystalline structures. These results are consistent with the conclusions drawn from MAS ${ }^{13} \mathrm{C}$ NMR and DSC.

\subsection{Molecular dynamics of the blends iPP/sPP by solid state NMR}

Solid state NMR is a powerful tool for characterising and studying the structural and dynamic properties of polymers including blends of them. The possibility of performing selective experiments renders this spectroscopy particularly interesting for analysing the structure and the dynamic of polymers. The measurement of relaxation times should get information on local structure in the blend $\mathrm{iPP} / \mathrm{sPP}$ isolating phases with different mobilities.

Relaxation times of solid polymers are not only determined by dynamic phenomena. There exists a contribution from the static mechanism of spin diffusion [18]. When two proton populations have different spin temperatures at a given time, they will tend to a common spin temperature by spin diffusion. Such a situation occurs during $T_{1}\left({ }^{1} \mathrm{H}\right)$ and $T_{1 \rho}\left({ }^{1} \mathrm{H}\right)$ determinations in systems which may contain heterogeneities. According to these considera- 
tions, it has been estimated that for polymeric systems, spin diffusion will be efficient at length scales of the order of 10 and $1 \mathrm{~nm}$ during $T_{1}\left({ }^{1} \mathrm{H}\right)$ and $T_{1 \rho}\left({ }^{1} \mathrm{H}\right)$ measurements respectively. These measurements are therefore interesting to characterize localized motion in the materials.

\subsubsection{Broad line ${ }^{1} \mathrm{H}$ NMR: spin-lattice relaxation time in the laboratory frame of proton $\left(T_{1}\left({ }^{1} \mathrm{H}\right)\right)$}

$T_{1}\left({ }^{1} \mathrm{H}\right)$ has been determined at $25^{\circ} \mathrm{C}$ for the blends $\mathrm{iPP} / \mathrm{sPP}$ and its evolution as a function of the composition of the blend is shown in Table 4. For each blend, only one $T_{1}\left({ }^{1} \mathrm{H}\right)$ has been found meaning that there is no heterogeneity of mobility having diffusion length higher than $10 \mathrm{~nm}$. It can be explained by the spin diffusion phenomenon and because of the close value of $T_{\mathrm{g}}$ with the room temperature. Indeed $T_{\mathrm{g}}$ lies between -10 and $0^{\circ} \mathrm{C}$ for iPP and sPP and the mobility difference between the polymeric chains of the blends are similar leading to only one value of $T_{1}\left({ }^{1} \mathrm{H}\right)$.

As shown in Table 4, sPP exhibits the highest value of $T_{1}\left({ }^{1} \mathrm{H}\right)$. An increase of $T_{1}\left({ }^{1} \mathrm{H}\right)$ corresponds to the reduction of the molecular mobility and sPP is the material having the lowest molecular mobility among the analyzed materials. The blends $75 / 25,50 / 50$ and $30 / 70$ exhibit similar $T_{1}\left({ }^{1} \mathrm{H}\right)$ values closed to that of virgin iPP. On the contrary, the blend 40/60 exhibit a $T_{1}\left({ }^{1} \mathrm{H}\right)$ value intermediate between those of virgin polypropylenes. It indicates that the molecular mobility is less with this composition of blend because of

Table 4. $T_{1}\left({ }^{1} \mathrm{H}\right)$ of the blend $\mathrm{iPP} / \mathrm{sPP}$ at $25^{\circ} \mathrm{C}$ as a function of the composition

\begin{tabular}{|l|c|}
\hline \multicolumn{1}{|c|}{ Material } & $\begin{array}{c}\mathbf{T}_{\mathbf{1}}\left({ }^{\mathbf{1}} \mathbf{H}\right) \\
{[\mathbf{s}]}\end{array}$ \\
\hline Virgin iPP & 0.95 \\
\hline iPP/sPP $(75 / 25)$ & 0.86 \\
\hline $\mathrm{iPP} / \mathrm{sPP}(50 / 50)$ & 0.88 \\
\hline $\mathrm{iPP} / \mathrm{sPP}(40 / 60)$ & 1.10 \\
\hline $\mathrm{iPP} / \mathrm{sPP}(30 / 70)$ & 0.93 \\
\hline Virgin sPP & 1.19 \\
\hline
\end{tabular}

the particular the morphology of the blend exhibiting co-continuous phases.

\subsubsection{Broad line ${ }^{1} H$ NMR: spin-lattice relaxation time in the rotating frame of proton $\left(T_{1 \rho}\left({ }^{1} \mathrm{H}\right)\right)$}

In order to limit the number of measurement, only the blend $\mathrm{iPP} / \mathrm{sPP}$ 30/70 compared to the virgin polypropylenes was examined. For each material, three distinct $T_{1 \rho}\left({ }^{1} \mathrm{H}\right)$ values have been found (Table 5). $\left.T_{1 \rho}\left({ }^{1} \mathrm{H}\right)\right)$ is sensitive at shorter scale than $T_{1}\left({ }^{1} \mathrm{H}\right)$ and different zones of mobility can be detected. Recognizing that shorter $T_{1 \rho}\left({ }^{1} \mathrm{H}\right)$ is associated to the decrease of molecular mobility, longer $T_{1 \rho}\left({ }^{1} \mathrm{H}\right)$, $T_{1 \text { plong }}\left({ }^{1} \mathrm{H}\right)$, is assigned to crystalline regions, the shortest $T_{1 \rho}\left({ }^{1} \mathrm{H}\right), T_{1 \rho s h o r t}\left({ }^{1} \mathrm{H}\right)$, is assigned to free amorphous regions, and the intermediate $T_{1 \rho}\left({ }^{1} \mathrm{H}\right)$, $T_{1 \text { pinter }}\left({ }^{1} \mathrm{H}\right)$, is assigned to constrained amorphous regions. In semi-crystalline materials, the constrained amorphous zones correspond to amorphous zones at the interface amorphous phase - crystalline phase between the crystalline lamellae [18]. Nevertheless, the immiscibility character and the morphology of the blends iPP/sPP also suggest that the constrained amorphous zone could incorporate amorphous polymeric chains located at the interface matrix - nodule. This assumption will be further considered and discussed when investigating the measurements of $T_{1 \rho}(\mathrm{C})$.

From Table 5, it is observed that the $T_{1 \rho}\left({ }^{1} \mathrm{H}\right)$ values of the components 'long' and 'intermediate' decrease when increasing the concentration of sPP. It indicates the mobilities of the crystalline regions and the constrained amorphous regions increase when incorporating $\mathrm{sPP}$ in the blends $\mathrm{iPP} / \mathrm{sPP}$. In the case of the short component, the $T_{1 \text { pshort }}\left({ }^{1} \mathrm{H}\right)$ value of the blend iPP/sPP 30/70 is smaller than those of virgin polypropylenes with the highest number of associated protons. It shows a higher molecular mobility of the free amorphous regions in the blend than in iPP and sPP. It shows that interactions take place between the amorphous phases of iPP and sPP in

Table 5. $T_{1 \rho}\left({ }^{1} \mathrm{H}\right)$ of the blend iPP/sPP $(30 / 70)$ compared to virgin polypropylenes

\begin{tabular}{|c|c|c|c|c|c|c|}
\hline \multirow[t]{2}{*}{ Material } & \multicolumn{2}{|c|}{ Component 'long' } & \multicolumn{2}{|c|}{ Component 'intermediate' } & \multicolumn{2}{|c|}{ Component 'short' } \\
\hline & $\begin{array}{c}\mathrm{T}_{1 \rho \mathrm{\rho long}}\left({ }^{1} \mathrm{H}\right) \\
{[\mathrm{ms}]}\end{array}$ & $\%^{1} \mathbf{H}_{\text {long }}$ & $\begin{array}{c}\mathrm{T}_{1 \text { pinter }}\left({ }^{1} \mathrm{H}\right) \\
{[\mathrm{ms}]}\end{array}$ & $\%{ }^{1} \mathbf{H}_{\text {inter }}$ & $\begin{array}{c}\mathrm{T}_{1 \rho \mathrm{pshort}}\left({ }^{1} \mathrm{H}\right) \\
{[\mathrm{ms}]}\end{array}$ & $\%^{1} \mathbf{H}_{\text {short }}$ \\
\hline Virgin iPP & 51 & 42 & 7 & 22 & 0.8 & 36 \\
\hline iPP/sPP $(30 / 70)$ & 38 & 31 & 4 & 23 & 0.5 & 46 \\
\hline Virgin sPP & 18 & 30 & 2 & 18 & 0.6 & 52 \\
\hline
\end{tabular}


the blend enhancing the molecular mobility of the amorphous polymeric chains.

\subsubsection{High resolution ${ }^{13} \mathrm{C}$ NMR: Spin-lattice relaxation time in the rotating frame of carbon $\left(T_{1 \rho}(C)\right)$}

$T_{1 \rho}(\mathrm{C})$ measurement via high resolution ${ }^{13} \mathrm{C}$ NMR experiment has the advantage to be selective since the measurement is done via selected carbons. It permits to get localized information and in particular about protons in the vicinity of the carbons. Hence evolution curve of $T_{1 \rho}(\mathrm{C})$ gives the molecular dynamic associated to each carbon of the polymeric chain.

$T_{1 \rho}(\mathrm{C})$ as a function of the composition. Three components of $T_{1 \rho}(\mathrm{C})$ have been determined for the methylene carbons of iPP and sPP (see Figure 7). The short, intermediate and long components are assigned to amorphous, constrained amorphous and crystalline regions. Table 6 shows the evolutions of each component of $T_{1 \rho}(\mathrm{C})$ as a function of methylene carbons and of the concentration of sPP in the blend. Note that $\mathrm{CH}_{2}$ (a) of sPP corresponds to $\mathrm{CH}_{2}$ located on the periphery of the $4_{1}$ helix while $\mathrm{CH}_{2}$ (b) of sPP corresponds to $\mathrm{CH}_{2}$ located on the main axis of the helix.

The evolution of $T_{1 \rho}(\mathrm{C})$ of the methylene carbons of sPP depends on the composition of the blends which shows different dynamics as a function of the location of $\mathrm{CH}_{2}$ in the helical $4_{1}$ conformation. In the blend iPP/sPP 75/25, the $\mathrm{CH}_{2}$ groups of iPP and the $\mathrm{CH}_{2}$ (a) and $\mathrm{CH}_{2}$ (b) groups of sPP exhibit similar values of $T_{1 \text { pshort }}(\mathrm{C})$ and they have values between that of $\mathrm{CH}_{2}$ of iPP and that of $\mathrm{CH}_{2}$ (a) of sPP. This result evidences the miscibility of the free amorphous zones in the vicinity of the $\mathrm{CH}_{2}$ groups of the blend $[18,28,29]$. The intermediate components are also similar and the $T_{1 \text { pinter }}(\mathrm{C})$ values are between the values of $\mathrm{CH}_{2}$ of iPP and of $\mathrm{CH}_{2}(\mathrm{~b})$ of sPP which means also the miscibility of the con- strained amorphous zones. On the contrary, the $T_{1 \text { plong }}(\mathrm{C})$ values of the different $\mathrm{CH}_{2}$ of the blend are not similar which confirms as discussed in the previous sections the immiscibility of the crystalline zones. In addition to this, the $T_{1 \rho s h o r t}(\mathrm{C})$ values of $\mathrm{CH}_{2}$ (iPP) and $\mathrm{CH}_{2}$ (a) (sPP) are very close to those of virgin iPP and virgin SPP: it indicates that the presence of a second component in the blend does not modify significantly the molecular mobility of the crystalline zones of iPP and sPP in the vicinity of the methylene carbons. It evidences therefore there is no interaction between the crystalline regions in the blend $\mathrm{iPP} / \mathrm{sPP} 75 / 25$.

In the blend $\mathrm{iPP} / \mathrm{sPP} 30 / 70$, the $T_{1 \text { pshort }}(\mathrm{C})$ values of $\mathrm{CH}_{2}$ of iPP and of $\mathrm{CH}_{2}$ (b) of sPP are higher than those of the virgin polypropylenes. It shows the presence of strong interactions between the free amorphous regions. Nevertheless, there is no miscibility between the free amorphous phases since the $T_{1 \text { sshort }}(\mathrm{C})$ of $\mathrm{CH}_{2}$ of iPP and of $\mathrm{CH}_{2}$ (b) are different. The $T_{1 \text { pshort }}(\mathrm{C})$ of $\mathrm{CH}_{2}$ (a) of sPP (in the blend) is lower than that of virgin SPP. This increase of the molecular mobility is probably due to interactions enhancing the mobility of the amorphous zones located around $\mathrm{CH}_{2}$ (a). Concerning the $T_{1 \text { pinter }}(\mathrm{C})$ values, they are similar to those of the virgin polypropylenes and no conclusion can be drawn for the constrained amorphous zones. The $T_{1 \text { plong }}(\mathrm{C})$ values of $\mathrm{CH}_{2}$ (iPP) and $\mathrm{CH}_{2}$ (b) are similar and there is no interaction between the crystalline regions.

In the blend $\mathrm{iPP} / \mathrm{sPP} 50 / 50$, the three methylene groups exhibit $T_{1 p \text { short }}(\mathrm{C}), T_{1 \text { inter }}(\mathrm{C})$ and $T_{1 \text { plong }}(\mathrm{C})$ values different of the virgin polypropylenes which indicates the immiscibility between the free amorphous, constrained amorphous and crystalline regions. The $T_{1 \rho s h o r t}(\mathrm{C})$ values for the $\mathrm{CH}_{2}$ of iPP and $\mathrm{CH}_{2}$ (a) of sPP are higher and less respectively than those determined for the virgin polypropylenes suggesting interactions between the free amorphous zones. The $T_{1 \text { inter }}(\mathrm{C})$ values of the methylene car-

Table 6. $T_{1 \rho}(\mathrm{C})$ of the methylene carbons of iPP and sPP in the blend iPP/sPP 30/70 as a function of composition

\begin{tabular}{|c|c|c|c|c|c|c|c|c|c|}
\hline \multirow{3}{*}{$\begin{array}{c}\text { Composi- } \\
\text { tion } \\
\text { iPP/sPP }\end{array}$} & \multicolumn{3}{|c|}{$\mathrm{CH}_{2}$ (iPP) } & \multicolumn{3}{|c|}{$\mathrm{CH}_{2}$ (a) (sPP) } & \multicolumn{3}{|c|}{$\mathrm{CH}_{2}$ (b) (sPP) } \\
\hline & \multicolumn{9}{|c|}{ Component } \\
\hline & $\begin{array}{c}\mathrm{T}_{1 \rho \text { short }}(\mathrm{C}) \\
{[\mathrm{ms}]}\end{array}$ & $\begin{array}{c}\mathbf{T}_{\text {1pintermediate }}(\mathrm{C}) \\
{[\mathrm{ms}]}\end{array}$ & $\begin{array}{c}\mathrm{T}_{\text {1plong }}(\mathrm{C}) \\
{[\mathrm{ms}]}\end{array}$ & $\begin{array}{c}\mathrm{T}_{1 \rho s h o r t}(\mathrm{C}) \\
{[\mathrm{ms}]}\end{array}$ & $\begin{array}{c}\mathbf{T}_{1 \text { pintermediate }}(\mathrm{C}) \\
{[\mathrm{ms}]}\end{array}$ & $\begin{array}{c}T_{\text {1plong }}(\mathrm{C}) \\
{[\mathrm{ms}]}\end{array}$ & $\begin{array}{c}\mathrm{T}_{1 \mathrm{pshort}}(\mathrm{C}) \\
\mathrm{ms}]\end{array}$ & $\underset{[\mathrm{ms}]}{\mathbf{T}_{1 \text { pintermediate }}(\mathrm{C})}$ & $\begin{array}{c}\mathrm{T}_{\text {1plong }}(\mathrm{C}) \\
{[\mathrm{ms}]}\end{array}$ \\
\hline $100 / 0$ & 0.51 & 2.5 & 7.1 & $\mathrm{~N} / \mathrm{A}$ & N/A & $\mathrm{N} / \mathrm{A}$ & N/A & N/A & N/A \\
\hline $75 / 25$ & 0.80 & 2.9 & 8.2 & 0.80 & 1.8 & 7.5 & 0.8 & 1.9 & 4.0 \\
\hline $50 / 50$ & 0.78 & 3.5 & 9.8 & 0.45 & 1.6 & 5.1 & 0.40 & 1.7 & 7.1 \\
\hline $30 / 70$ & 0.78 & 2.0 & 6.8 & 0.48 & 2.0 & 4.2 & 0.85 & 1.7 & 6.8 \\
\hline $0 / 100$ & N/A & N/A & N/A & 0.60 & 2.1 & 6.8 & 0.51 & 2.2 & 6.5 \\
\hline
\end{tabular}


bons of iPP are higher than that in the virgin iPP while the values for the two types of $\mathrm{CH}_{2}$ of sPP are less than those measured for the virgin sPP. It indicates therefore interactions between the constrained zones of iPP and sPP.

The measurements of $T_{1 \rho}(\mathrm{C})$ values show that there are large interactions between free amorphous regions and constrained amorphous regions in the blends iPP/sPP $75 / 25$ and 30/70. These blends exhibit morphologies consisting in a matrix in which nodules of the minor component are dispersed. In addition to this, the results show a partial miscibility between the amorphous regions of iPP and sPP in the blend iPP/sPP 75/25. On the other hand, the miscibility of the amorphous regions of the blend iPP/sPP 50/50 remains questionable. It was shown there are interactions in the free amorphous regions and in the constrained zones: the specific morphology of the blend (co-continuous phases) can be an explanation of this.

Table 7. $T_{1 \rho}(\mathrm{C})$ of the methylene carbons of iPP as a function of temperature

\begin{tabular}{|c|c|c|c|}
\hline \multirow{3}{*}{$\begin{array}{c}\text { Temperature } \\
\left.{ }^{\circ} \mathrm{C}\right]\end{array}$} & \multirow{2}{*}{\multicolumn{3}{|c|}{$\begin{array}{c}\mathrm{CH}_{2} \text { (iPP) } \\
\text { Component }\end{array}$}} \\
\hline & & & \\
\hline & $\begin{array}{c}\mathrm{T}_{1 \rho \text { short }}(\mathrm{C}) \\
{[\mathrm{ms}]}\end{array}$ & $\begin{array}{c}\mathbf{T}_{1 \text { pintermediate }}(\mathrm{C}) \\
{[\mathrm{ms}]}\end{array}$ & $\begin{array}{c}T_{\text {1plong }}(\mathrm{C}) \\
{[\mathrm{ms}]}\end{array}$ \\
\hline 25 & 0.2 & 2.7 & 7.2 \\
\hline 50 & 0.2 & 3.1 & 15.1 \\
\hline 80 & 0.7 & - & 7.9 \\
\hline 100 & 9.0 & - & 11.1 \\
\hline
\end{tabular}

$T_{1 \rho}(\mathrm{C})$ as a function of the temperature. The reason of measuring $T_{1 \rho}(\mathrm{C})$ as a function of temperature is to get better understanding on the organization of the blend iPP/sPP in the solid state. The evolution of the methylene carbons as function of temperature is listed in Table 7 for virgin iPP, in Table 8 for virgin sPP and Table 9 for the blend iPP/sPP 30/70.

The temperature rise modifies the number of components in the calculation of $T_{1 \rho}(\mathrm{C})$. The intermediate component associated to a constrained amorphous region disappears at temperature higher than $50^{\circ} \mathrm{C}$. It is explained by the relaxation $\alpha^{*}\left(T_{\alpha^{*}}\right.$ is about $80-90^{\circ} \mathrm{C}$ ) leading to higher mobility between the crystalline chains (motion of the crystalline lamellae in which are the amorphous chains). Hence, the constrained amorphous zones appear as free in terms of $T_{1 \rho}(\mathrm{C})$. In the case of virgin sPP, three components of $T_{1 \rho}(\mathrm{C})$ are detected at room temperature but with the temperature rise, the intermediate component of $\mathrm{CH}_{2}$ (b) also disappears from $80^{\circ} \mathrm{C}$. This disappearance of the constrained amorphous zone in the vicinity of $\mathrm{CH}_{2}$ (b) is linked to the low melting temperature of $\mathrm{sPP}\left(130^{\circ} \mathrm{C}\right)$ which leads to the decrease of crystalline zones and therefore of the constrained amorphous zones.

In the case of the blend iPP/sPP 30/70, temperature changes do not modify the number of components of $T_{1 \rho}(\mathrm{C})$. According to our previous discussion on the disappearance of the intermediate component, it suggests that the intermediate carbons are assigned to constrained amorphous zones located in the

Table 8. $T_{1 \rho}(\mathrm{C})$ of the methylene carbons of sPP as a function of temperature

\begin{tabular}{|c|c|c|c|c|c|c|}
\hline \multirow{3}{*}{$\begin{array}{c}\text { Temperature } \\
{\left[{ }^{\circ} \mathrm{C}\right]}\end{array}$} & \multicolumn{3}{|c|}{ CH (a) (sPP) } & \multicolumn{3}{|c|}{$\mathrm{CH}$ (b) (sPP) } \\
\hline & \multicolumn{6}{|c|}{ Component } \\
\hline & $\begin{array}{c}T_{1 \rho s h o r t}(C) \\
{[\mathrm{ms}]}\end{array}$ & $\begin{array}{c}\mathbf{T}_{\text {1pintermediate }}(\mathrm{C}) \\
{[\mathrm{ms}]}\end{array}$ & $\begin{array}{c}T_{\text {1plong }}(\mathrm{C}) \\
{[\mathrm{ms}]}\end{array}$ & $\begin{array}{c}\mathbf{T}_{1 \rho s h o r t}(\mathrm{C}) \\
{[\mathrm{ms}]}\end{array}$ & $\begin{array}{c}\mathbf{T}_{1 \text { pintermediate }}(\mathrm{C}) \\
{[\mathrm{ms}]}\end{array}$ & $\begin{array}{c}T_{1 \text { long }}(C) \\
{[\mathrm{ms}]}\end{array}$ \\
\hline 25 & 0.3 & 3.0 & 7.1 & 0.2 & 1.6 & 7.6 \\
\hline 50 & 0.2 & 2.9 & 21.7 & 0.2 & 4.3 & 21.0 \\
\hline 80 & 0.8 & 3.5 & 7.1 & 0.2 & 3.9 & 20.9 \\
\hline 100 & 0.2 & 6.0 & 23.7 & 3.3 & $\begin{array}{ll}- \\
-\end{array}$ & 38.4 \\
\hline
\end{tabular}

Table 9. $T_{1 \rho}(\mathrm{C})$ of the methylene carbons of iPP and sPP in the blend iPP/sPP 30/70 as a function of temperature

\begin{tabular}{|c|c|c|c|c|c|c|c|c|c|}
\hline \multirow{3}{*}{$\begin{array}{c}\text { Temper- } \\
\text { ature } \\
{\left[{ }^{\circ} \mathrm{C}\right]}\end{array}$} & \multicolumn{3}{|c|}{$\mathrm{CH}_{2}$ (iPP) } & \multicolumn{3}{|c|}{$\mathrm{CH}_{2}$ (a) (sPP) } & \multicolumn{3}{|c|}{$\mathrm{CH}_{2}$ (b) (sPP) } \\
\hline & \multicolumn{9}{|c|}{ Component } \\
\hline & $\begin{array}{c}\mathbf{T}_{1 \rho \text { short }}(\mathrm{C}) \\
{[\mathrm{ms}]}\end{array}$ & $\begin{array}{c}\mathbf{T}_{\text {1pintermediate }}(\mathbf{C}) \\
{[\mathrm{ms}]}\end{array}$ & $\begin{array}{c}T_{1 \rho l o n g}(C) \\
{[\mathrm{ms}]}\end{array}$ & $\begin{array}{c}T_{1 \rho s h o r t}(C) \\
{[\mathrm{ms}]}\end{array}$ & $\begin{array}{c}\mathbf{T}_{1 \text { pintermediate }}(\mathrm{C}) \\
{[\mathrm{ms}]}\end{array}$ & $\begin{array}{c}T_{\text {1plong }}(\mathrm{C}) \\
{[\mathrm{ms}]}\end{array}$ & $\begin{array}{c}\mathbf{T}_{1 \rho s h o r t}(\mathrm{C}) \\
{[\mathrm{ms}]}\end{array}$ & $\begin{array}{c}\mathbf{T}_{\text {1pintermediate }}(\mathrm{C}) \\
{[\mathrm{ms}]}\end{array}$ & $\begin{array}{c}T_{1 \rho l o n g}(C) \\
{[\mathrm{ms}]}\end{array}$ \\
\hline 25 & 0.3 & 4.5 & 16.2 & 0.20 & 2.8 & 37.2 & 0.15 & 4.6 & 7.3 \\
\hline 50 & 0.2 & 3.5 & 17.1 & 0,20 & 3.6 & 8.2 & 0.20 & 4.5 & 15.1 \\
\hline 80 & 0.5 & 4.8 & 19.6 & 0.08 & 2.3 & 12.5 & 0.15 & 3.5 & 12.2 \\
\hline 100 & 0.3 & 5.5 & 20.4 & 0.50 & 4.2 & 13.8 & 0,20 & 4.6 & 27.4 \\
\hline
\end{tabular}




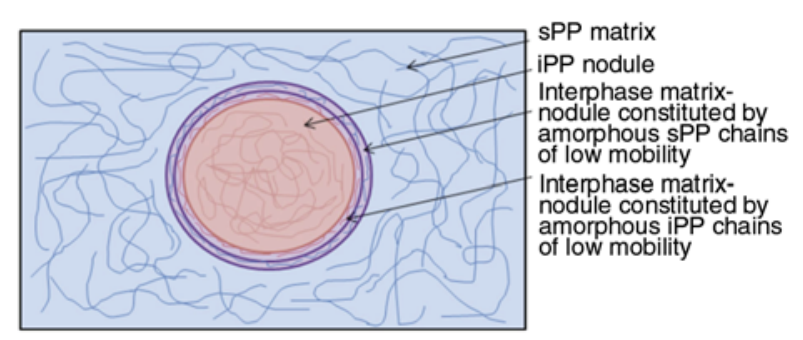

Figure 8. Scheme of the amorphous zones located at the interface matrix-nodule in the blend $\mathrm{iPP} / \mathrm{sPP}$ $30 / 70$

blend at the interface matrix-nodule in which the amorphous chains of iPP and sPP are involved (Figure 8).

In the blend $\mathrm{iPP} / \mathrm{sPP} 30 / 70$, the $T_{1 \text { pshort }}(\mathrm{C})$ values of the methylene protons are almost constant from $80^{\circ} \mathrm{C}$. It shows that the mobility of the amorphous zones of the blend is less sensitive than those of the virgin polypropylenes where the variations are more significant. On the other hand, the molecular mobility of the crystalline regions associated to $\mathrm{CH}_{2}$ of iPP and to $\mathrm{CH}_{2}$ (b) of sPP decreases slightly with the temperature rise. The mobility of $\mathrm{CH}_{2}$ (a) of sPP (periphery of the helix) remains constant at temperatures higher than $50^{\circ} \mathrm{C}$ while a strong increase of the mobility is observed from 25 to $50^{\circ} \mathrm{C}$.

The amorphous regions in the blend iPP/sPP 30/70 shows different changes as a function of the temperature. In the vicinity of $\mathrm{CH}_{2}$ of iPP, they exhibit the highest mobility at $50^{\circ} \mathrm{C}$ and the lowest one at $100^{\circ} \mathrm{C}$. The mobility of the constrained amorphous zones in the vicinity of $\mathrm{CH}_{2}$ (b) remain almost constant over the examined temperature range. Finally, the constrained amorphous zones in the vicinity of $\mathrm{CH}_{2}$ (a) exhibit minimum mobility at 50 and $100^{\circ} \mathrm{C}$ while it is maximum at 25 and $80^{\circ} \mathrm{C}$. The highest mobility is observed for the methylene carbons of sPP at $80^{\circ} \mathrm{C}$.

\subsection{Discussion}

The different analyses done in this paper have characterized the morphology and the structure of the blends iPP/sPP as a function of their composition. DSC has revealed that crystallization of $\mathrm{iPP}$ and $\mathrm{sPP}$ occurs separately in the blends $\mathrm{iPP} / \mathrm{sPP}$. The apparent immiscibility of the two components of the blends is confirmed by electronic microscopy (SEM and TEM). It is shown that the blends $\mathrm{PP} / \mathrm{sPP}$ exhibit biphasic structures constituted by a polymeric matrix (the main component) in which are dispersed nod- ules (minor component). Nevertheless, the compositions $50 / 50$ and $40 / 60$ are similar as a structure constituted of co-continuous phases which are characteristic of equi-mass concentration blends of immiscible polymers. This observation suggests that a co-continuous structure should be obtained for a composition lying between 50/50 and 40/60. The separation of the crystalline phases of each component of the blends has been evidenced by WAXD and by MAS ${ }^{13} \mathrm{C}$ NMR. WAXD of the different blends shows the crystalline forms of each component of the blend as they are in the pure polypropylenes. iPP and sPP in the blends crystallize under the most stable forms, namely the $\alpha$ form for iPP and the form I for sPP (in this last case, defects in the chain packing are detected). Same conclusions are done from MAS 13C NMR and DSC analyses.

Relaxation times' measurements $T_{1 \rho}\left({ }^{1} \mathrm{H}\right)$ and $T_{1 \rho}(\mathrm{C})$ have evidenced there are strong interactions between the amorphous phases of iPP and sPP in the blends which modify significantly the molecular mobility in the phases. These measurements have shown the partial miscibility of the amorphous zones in the blend iPP/sPP 75/25 but it remains unclear for the composition 30/70 in which the continuous phase is sPP instead of iPP. The miscibility of the amorphous phases disappears in the blend iPP/sPP 50/50 because of the specific morphology of the blend. Those results show the dependence of the morphology (and therefore the composition of the blend) on the miscibility of the amorphous phases of iPP and sPP. The component related to constrained amorphous phases in the virgin polypropylenes disappear when increasing temperature because of the $\alpha^{*}$ relaxation in iPP $\left(80^{\circ} \mathrm{C}\right)$ and of the proximity of the melting temperature of $\mathrm{sPP}\left(130^{\circ} \mathrm{C}\right)$. On the other hand, this component does not disappear as a function of the temperature in the blends and it suggests the formation of specific zone containing constrained amorphous polymeric chains at the interphase matrix-nodule.

\section{Conclusions}

In this paper, the morphology and the structural properties of blends iPP/sPP have been investigated by different techniques. It has been shown the influence of the composition of the blends on the morphology of the materials. The morphology is then directly related to the structural organization of the blends. The crystallization rate decreases as a function of 
the sPP content. The minor component is dispersed as a nodule in the main component of the blend and it plays the role of nucleating agent on it. Besides, morphology changes occur for the composition $50 / 50$ of the blend iPP/sPP. Different phases have been identified, namely free amorphous, constrained amorphous and crystalline regions which exhibit different molecular mobilities. It is also shown an additional constrained amorphous zone due to nodules at the interphase matrix-nodule.

\section{Acknowledgements}

The present work was part of the MEMOTI project which was financially supported by the Ministère de l'Economie, de l'industrie et de l'emploi and in particular the Direction Générale des Entreprises. The UpTex competitive cluster is also acknowledged for administrative assistance in this project.

\section{References}

[1] Natta G., Pasquon I., Zambelli A.: Stereospecific catalysts for the head-to-tail polymerization of propylene to a crystalline syndiotactic polymer. Journal of the American Chemical Society, 84, 1488-1490 (1962). DOI: $10.1021 / \mathrm{ja} 00867 \mathrm{a} 029$

[2] Ewen J. A., Jones R. L., Razavi A., Ferrara J. D.: Syndiospecific propylene polymerizations with Group IVB metallocenes. Journal of the American Chemical Society, 110, 6255-6256 (1988). DOI: $10.1021 / \mathrm{ja} 00226 \mathrm{a} 056$

[3] De Rosa C., De Ballesteros O. R., Auriemma F.: Mechanical properties of helical and mesomorphic forms of syndiotactic polypropylene at different temperatures. Macromolecules, 37, 7724-7735 (2004). DOI: $10.1021 / \mathrm{ma} 049214 \mathrm{~h}$

[4] De Rosa C., Auriemma F.: Structure and physical properties of syndiotactic polypropylene: A highly crystalline thermoplastic elastomer. Progress in Polymer Science, 31, 145-237 (2006).

DOI: 10.1016/j.progpolymsci.2005.11.002

[5] Zhang X., Zhao Y., Wang Z., Zheng C., Dong X., Su Z., Sun P., Wang D., Han C. C., Xu D.: Morphology and mechanical behavior of isotactic polypropylene (iPP)/ syndiotactic polypropylene (sPP) blends and fibers. Polymer, 46, 5956-5965 (2005).

DOI: $10.1016 /$ j.polymer.2005.05.004

[6] Supaphol P., Spruiell J. E.: Isothermal melt- and coldcrystallization kinetics and subsequent melting behavior in syndiotactic polypropylene: A differential scanning calorimetry study. Polymer, 42, 699-712 (2001). DOI: 10.1016/S0032-3861(00)00399-2
[7] Thomann R., Kressler J., Setz S., Wang C., Mülhaupt R.: Morphology and phase behaviour of blends of syndiotactic and isotactic polypropylene: 1 . X-ray scattering, light microscopy, atomic force microscopy, and scanning electron microscopy. Polymer, 37, 26272634 (1996).

DOI: 10.1016/0032-3861(96)87621-X

[8] Clancy T. C., Pütz M., Weinhold J. D., Curro J. G., Mattice W. L.: Mixing of isotactic and syndiotactic polypropylenes in the melt. Macromolecules, 33, 94529463 (2000).

DOI: $10.1021 / \mathrm{ma} 0011035$

[9] Woo E. M., Cheng K. Y., Chen Y-F., Su C. C.: Experimental verification on UCST phase diagrams and miscibility in binary blends of isotactic, syndiotactic, and atactic polypropylenes. Polymer, 48, 5753-5766 (2007). DOI: 10.1016/j.polymer.2007.07.015

[10] Phillips R. A.: Macromorphology of polypropylene homopolymer tacticity mixtures. Journal of Polymer Science Part B: Polymer Physics, 38, 1947-1964 (2000).

DOI: 10.1002/1099-0488(20000801)38:15<1947::aidpolb10>3.0.co;2-m

[11] Wang Z-G., Phillips R. A., Hsiao B. S.: Morphology development during isothermal crystallization. II. isotactic and syndiotactic polypropylene blends. Journal of Polymer Science Part B: Polymer Physics, 39, 1876-1888 (2001).

DOI: $10.1002 /$ polb.1162

[12] Zou X-X., Yang W., Zheng G-Q., Xie B-H., Yang MB.: Crystallization and phase morphology of injectionmolded isotactic polypropylene (iPP)/syndiotactic polypropylene (sPP) blends. Journal of Polymer Science Part B: Polymer Physics, 45, 2948-2955 (2007). DOI: $10.1002 /$ polb.21237

[13] Gorrasi G., Vittoria V., Longo P.: Transport and mechanical properties of iPP-sPP fibers. Journal of Applied Polymer Science, 80, 539-545 (2001).

DOI: $10.1002 / 1097-4628(20010425) 80: 4<539::$ aidapp1128>3.0.co;2-3

[14] Zheng C-X., Zhang X-Q., Rottstegge J., Dong X., Zhao Y., Wang D-J., Zhu S-N., Wang Z-G., Han C. C., Xu D-F.: Preliminary investigation on the miscibility of isotactic polypropylene (iPP) and syndiotactic polypropylene (sPP) blends. Chinese Journal of Polymer Science, 24, 569-573 (2006).

DOI: $10.1142 / \mathrm{s} 0256767906001655$

[15] da Silva N. M., Tavares M. I. B., Stejskal E. O.: ${ }^{13}$ Cdetected ${ }^{1} \mathrm{H}$ spin diffusion and ${ }^{1} \mathrm{H}$ relaxation study of multicomponent polymer blends. Macromolecules, 33, 115-119 (2000). DOI: $10.1021 / \mathrm{ma} 980798 \mathrm{v}$

[16] White J. L., Wachowicz M.: Polymer blend miscibility. in 'Annual reports on NMR spectroscopy' (ed.: Webb G. A.) Vol 64, 189-209 (2008). 
[17] McBrierty V. J.: Heterogeneity in polymers as studied by nuclear magnetic resonance. Faraday Discussions of the Chemical Society, 68, 78-86 (1979).

DOI: $10.1039 / \mathrm{dc} 9796800078$

[18] McBrierty V. J., Douglass D. C.: Recent advances in the NMR of solid polymers. Journal of Polymer Science: Macromolecular Reviews, 16, 295-366 (1981). DOI: 10.1002/pol.1981.230160105

[19] McBrierty V. J., Ward I. M.: Investigation of the orientation distribution functions in drawn polyethylene by broad line nuclear magnetic resonance. Journal of Physics D: Applied Physics, 1, 1529-1542 (1968). DOI: $10.1088 / 0022-3727 / 1 / 11 / 319$

[20] Chu C. W., Dickinson L. C., Chien J. C. W.: Study of critical phenomena of polystyrene-poly(vinyl methyl ether) blends by solid state NMR. Journal of Applied Polymer Science, 41, 2311-2325 (1990). DOI: 10.1002/app.1990.070410933

[21] Hjertberg T., Hargitai T., Reinholdsson P.: Carbon-13 CP-MAS NMR study on content and mobility of double bonds in poly(trimethylolpropane trimethacrylate). Macromolecules, 23, 3080-3087 (1990). DOI: $10.1021 / \mathrm{ma} 00214 \mathrm{a} 009$

[22] Le Menestrel C., Kenwright A. M., Sergot P., Lauprêtre F., Monnerie L.: Carbon-13 NMR investigation of local dynamics in compatible polymer blends. Macromolecules, 25, 3020-3026 (1992).

DOI: $10.1021 / \mathrm{ma} 00038 \mathrm{a} 003$

[23] Thomann R., Kressler J., Rudolf B., Mülhaupt R.: Morphology and phase behaviour of blends of syndiotactic and isotactic polypropylene: 2 . Differential scanning calorimetry, light transmission measurements, and PVT measurements. Polymer, 37, 2635-2640 (1996). DOI: 10.1016/0032-3861(96)87622-1
[24] Spaleck W., Antberg M., Rohrmann J., Winter A., Bachmann B., Kiprof P., Behm J., Herrmann W. A.: High molecular weight polypropylene through specifically designezirconocene catalysts. Angewandte Chemie International Edition in English, 31, 1347-1350 (1992). DOI: 10.1002/anie.199213471

[25] Galambos A., Wolkowicz M., Zeigler R.: Structure and morphology of highly stereoregular syndiotactic polypropylene produced by homogeneous catalysts. in 'Polymeric Materials Science and Engineering' (eds.: Vandenberg E. J., Salamone J. C.) ACS Symposium Series, Vol 496, 104-120 (1992). DOI: 10.1021/bk-1992-0496.ch008

[26] Garnier L., Duquesne S., Bourbigot S., Delobel R.: Nonisothermal crystallization kinetics of $\mathrm{iPP} / \mathrm{sPP}$ blends. Thermochimica Acta, 481, 32-45 (2009). DOI: $10.1016 / \mathrm{j}$. tca.2008.10.006

[27] Fričová O., Uhrínová M., Hronský V., Koval'aková M., Olčák D., Chodák I., Spěváček J.: High-resolution solid-state NMR study of isotactic polypropylenes. Express Polymer Letters, 6, 204-212 (2012). DOI: $10.3144 /$ expresspolymlett.2012.23

[28] Sozzani P., Simonutti R., Galimberti M.: MAS NMR characterization of syndiotactic polypropylene: Crystal structure and amorphous phase conformation. Macromolecules, 26, 5782-5789 (1993). DOI: $10.1021 / \mathrm{ma} 00073 \mathrm{a} 036$

[29] Dadayli D., Harris R. K., Kenwright A. M., Say B. J., Sünnetçioğlu M. M.: Solid-state ${ }^{1}$ H n.m.r. studies of polypropylene. Polymer, 35, 4083-4087 (1994). DOI: 10.1016/0032-3861(94)90579-7 